Analysis gave the following:

I. 0.2009 gram gave 0.1243 gram silver bromide.

II. 0.2008 gram gave 0.1237 gram silver bromicie.
Calculated for
Bromine............. 26.40
$\begin{array}{ll}\text { I. Foumcl. } \\ 26.32 & \text { II. } \\ 26.21\end{array}$

It should also be mentioned that in one preparation of this compound by boiling ethylisoeugenol dibromide with methyl alcohol, another compound was formed, together with the methyl alcohol addition-product; it was separated by fractional crystallization from ethyl alcohol in which it is more sparingly soluble than the addition-product. It crystallizes in fine needles and melts at I $28^{\circ}$; it contains no bromine, but has not been further investigated.

[CONTRIBUTION FROM THE NORTH CAROLINA AGRICULTURAI, FiXPFRIMTHT

STATION. COMMLNICATED BY W. A. WITHERS.]

\title{
THE DETERMINATION OF SULPHUR IN PLANTS.
}

\author{
BY G. S. FRAPM. \\ kerivel Dueraturs ign
}

I $\mathrm{N}$ a previous issue of this Journal' the author called attention to the loss of sulphur in preparing ash of plants. The conclusion reached was that "the sulphur obtained when the ash was burned by itself is from 4 to roo per cent. less than when burned with calcium acetate. Whether the calcium acetate retains all the sulphur or not, is a point which requires further study." The facts which will be presented here show that the calcium acetate does not retain all the sulphur.

The object of the work was to compare the calcium acetate method with some method by the use of which we could be reasonably certain that all the sulphur contained in the plant in inorganic or organic combination would be retained and determined. A great difficulty is that a very small amount of sulphur is contained in a large quantity of plant material. The Liebig method (fusion with potassium hydroxide and a small amount of potassium uitrate in a silver dish) and the Carius method (heating in a sealed tube with fuming nitric acid) were considered, but offered difficulties on account of the large quantity of organic material to be handled. The following method was finally adopted for trial:

Fifteen grams material were placed in a flat porcelain dish of about $250 \mathrm{cc}$. capacity, $35 \mathrm{cc}$. of nitric acid (conc.) added, and the 
mixture heated gently until the action had moderated. One gram potassium nitrate was then added, and the mixture evaporated to a thin paste, transferred to a platinum dish, evaporated on a water-bath, and ignited to an ash. After heating for some time, the ash was dissolved in dilute hydrochloric acid, the solution evaporated to dryness, and the residue dried thoroughly to render silica insoluble. It was moistened with a little dilute hydrochloric acid, evaporated, and again dried. The residue was moistened with about $5 \mathrm{cc}$. of hydrochloric acid, taken up with about $50 \mathrm{cc}$. of boiling water, filtered, and sulphuric acid determined in the filtrate by the usual method.

A blank determination with the reagents proved them to be free from sulphur. The sulphur (as sulphur trioxide) found by this method compared with the others is given in the following table:

\begin{tabular}{|c|c|c|c|}
\hline & $\begin{array}{c}\text { In ash } \\
\text { (usual way). } \\
\text { Per cent. }\end{array}$ & $\begin{array}{l}\text { In calcium } \\
\text { acetate ash. } \\
\text { Per cent. }\end{array}$ & $\begin{array}{l}\text { Nitric acid } \\
\text { method. } \\
\text { Per cent. }\end{array}$ \\
\hline Wheat bran ......... & $\cdots$ & $0.22 \mathrm{I}$ & 0.368 \\
\hline Cottonseed meal.... & $\cdots$ & 0.343 & 0.926 \\
\hline Green rape...$\ldots \ldots$ & . 1.02 & $\mathrm{I} .25$ & I. 63 \\
\hline Wheat bran $\ldots . . .$. & . 0.00 & o.I4 & 0.30 \\
\hline Corn silage...... & . 0.20 & 0.24 & 0.43 \\
\hline Timothy hay ....... & - $\quad 0.15$ & 0.17 & 0.28 \\
\hline
\end{tabular}

It is evident that the calcium acetate method does not give correct values for sulphur.

It is not believed that the loss of sulphur is due to volatilization of sulphates, but to the escape of organic sulphur compounds which are not burned or oxidized. Most of the sulphur in a plant is not in the form of sulphates, but is in an organic form, and it is not surprising that it is lost under the conditions. The same would be true of chlorine, which is probably much more difficult to retain than sulphur.

The following modification of the nitric acid method just described has been found more convenient. It calls for the use of a smaller quantity of material, and leaves out the platinum dish, which is liable to be damaged under certain conditions.

Five grams material are placed in a $3 \frac{\mathrm{I} / 2}{2}$ inch porcelain evaporating dish, $20 \mathrm{cc}$. of concentrated nitric acid added, and the mixture heated cautiously on the water-bath until all danger of overflowing has passed. It is then partly evaporated, ro cc. of a 
5 per cent. solution of potassium nitrate added, the mixture evaporated to dryness and ignited, at first gently, then under a blast-lamp, until the residue is white. It is then dissolved in hydrochloric acid, evaporated to dryness, and heated for some time in an air-bath to render silica insoluble. The residue is taken up in water with the addition of a little acid, filtered, and the sulphuric acid precipitated with barium chloride, etc., in the usual way.

[CONTRIBUTION FROM THE HAVEMHYER IABORATORIFS OF COIUMBIA [NIVERSITY, No. 6I].

\section{ON THE RELATION OF THE HEAT OF COMBUSTION TO THE SPECIFIC GRAVITY IN FATTY OILS.}

BY H. C. SHFRMAX AND J. Fi, SXLIT.

$\mathrm{F}^{\text {ROM data }}$ given in a previous paper' it was inferred that $F$ among the common fatty oils there exists a certain definite relation between the heat of combustion and the specific gravity. Thus, comparing such typical oils as those of linseed, poppyseed, maize, cottonseed, sesame, almond, and olive, we find that the decrease in drying properties is accompanied by a decrease in specific gravity and a nearly proportional increase in the calorific power, so that the product of these two values shows comparatively little variation. It also seemed probable fron the examination of a few samples which were known to have been oxidized by exposure, that such oxidation reduces the heat of combustion to nearly the same extent that it increases the specific gravity. We are now able to give additional data in support of each of these inferences.

The determinations of specific gravity and of heat of combustion have been made by the methods described in our previous paper and we are again indebted to Professor Atwater, for the privilege of doing a considerable part of the work in the laboratories of Wesleyan University. The heats of combustion given in the tables below are those obtained at constant volume; $i . e$, the results actually shown by the calorimeter. The corresponding values for combustion at constant pressure may be calculated as already explained. ${ }^{2}$

Table A shows the specific gravities and heats of combustion

1 This Journal, 23,154.

: Ibia, 23, 167 . 